QUARTERLY TECHNICAL PROGRESS REPORT

REPORT TYPE: Quarterly

REPORTING PERIOD: April 1, 1997 - June 30, 1997

PRINCIPAL INVESTIGATOR: Steven F. Coombs

DATE: August 25, 1997

DOE Award No: DE-FC22-95BC14935

Submitted By:

Pacific Operators Offshore, Inc.

205 E. Carrillo Street, Suite 200

Santa Barbara, CA 93101 


\section{FEASIBILITY OF OPTIMIZING RECOVERY AND RESERVES FROM A MATURE AND GEOLOGICAL COMPLEX MULTIPLE TURBIDITE OFFSHORE CALIFORNIA RESERVOIR THROUGH THE DRILLING AND COMPLETION OF A TRILATERAL HORIZONTAL WELL}

Cooperative Agreement: DE-FC22-95BC14935

Institution: Pacific Operators Offshore, Inc.

Report Date: August 25, 1997

Award Date: September 1, 1995

Anticipated Completion Date:

Funding for FY 1995: \$814,718

Program Manager: Steven F. Coombs

Principal Investigator: Pacific Operators Offshore, Inc.

C0-Participants: University of Southern California/ Coombs and Associates

Contracting Officer's Representative: Edith Allison

Reporting Period: April 1, 1997 - June 30, 1997

\section{Objectives}

The main objective of this project is to devise an effective redevelopment strategy to combat producibility problems related to the Repetto turbidite sequences of the Carpinteria Field. The lack of adequate reservoir characterization, high-water cut production, and scaling problems have in the past contributed to the field's low productivity.

To improve productivity and enhance recoverable reserves, the following specific goals are proposed:

- Develop an integrated database of all existing data from work done by the former ownership group.

- Expand reservoir drainage and reduce sand problems through horizontal well drilling and completion.

- Operate and validate reservoirs' conceptual model by incorporating new data from the proposed trilateral well.

- Transfer methodologies employed in geologic modeling and drilling multilateral wells to other operators with similar reservoirs.

\section{Summary of Technical Progress}

Since the last progress report (January - March, 1997) additional work has been completed in the area of well log interpretation and geological modeling. During this period an extensive effort was made to refine our 3-D geological model both in the area of a refined attribute model and an enhanced structural model. Also, efforts to refine our drilling plans for budget period II were completed during this reporting period.

\section{Task 1.2.1 - Stratigraphy and Micro lamination}




\section{Petrophysics}

A program to re-process many of the well logs in the field was initiated. This was necessary for two reasons: 1) Our prior 3-D geologic modeling efforts used a log data set that contained cut-offs applied by the log calculation package. Because of the way the 3-D modeling program works (EarthVision) it is more desirable to apply parameter cut-offs in the 3-D package. 2) Because of some additional water analysis data we recently obtained on the Chevron portion of the field we were able apply a much better water salinity relationship in the intervals below the G7.

Concentration on wells which had poorer response and less cumulative oil production than would have been anticipated by the operators suggests the following.

(1) Wells which had a substantial amount of net pay in the "F" sands and which did not have good pay in the "G" sands depleted early did not have high water cumulative water production. This suggests that water support and/or oil and water migration did not occur in these wells. Attempts to further define the conditions points to the need for additional fault modeling based on these premises.

(2) Examination of the logs, both open hole from the late drilling program and some of the cased hole logs of about the same vintage suggest that the "G" sands do tend to show changing oil water contacts. The "F-1" sand in particular shows some desaturation with time, but not clearly a change in the water surface. Since the "F-1" is the biggest single sand and may still contain the most potential oil we should consider the F-1 as a candidate for some flank support with water injection, perhaps following some additional measurement of zone pressures in these weak areas.

Also, during this period a determination of oil/water contacts in the wells penetrating the subthrust, and subsequent calculation of vertical depths and coordinates of water in wet zones, depths of oil in oil filled zones and verification graphically of all picks and calculations. This was done along with the re-verification of all markers from both the 51 wells in the subthrust, and the 198 wells in the suprathrust sections. There have been some recent challenges to previous data requiring a revisit of some of the markers. Missing from this work are a number of log markers from the wells on the P-240 lease and digitized logs from the state 3133 parcel, both of which are considered of lesser importance to the study due to fault separation and short term potential economic value. Data for subthrust markers was released for QC mapping.

Continuing feedback and evaluation of information from the rework program and the potential redrill program along with the refinement of the fault picks by the Geologists verifies some of the previously suspected relationships between log calculations and production results. This information should allow the construction of a new 3-D model that better represents the reservoir.

One unconfirmed point in the observation of the logs is the fact that most of the wells which have oil saturation in a particular sand or layer in the subthrust interval generally do not have any saturation in that sand in the suprathrust interval. This is true particularly on the P-0166 and in part of the SACS-3150 areas and has not been examined on the P-240 and the 3133 leases. It is anticipated that 
the construction of the next generation 3-D model will expand this understanding and define the areas over which this may apply, and provide an estimate of the potential for a horizontal well in the subthrust area.

In the reprocessing of logs in the subthrust of the 3150 (7911) lease, and in the light of the now available raw data for all the wells, it is noted that a high incidence of incorrectly digitized data, or data which had not been checked by the prior operator, is present on the wells drilled during the period from 1979 to 1984 . At least five of these wells have data that does not agree with the raw data, and requires some additional digitizing. Unfortunately some of these key well attributes should not be used in evaluation of the 3150 deep subthrust area until this has been resolved.

Well A-7, on which we speculated that the F-1 layer would produce if returned to production has been positive. We anticipate the same on Well A-3. It is believed that these wells are in an area in which the lower sands have a strong water influx, and the upper sands have much less. Isolating the lower sands may allow further production of the upper F sands.

Subthrust log data has been checked, but may not be final since attribute mapping has not been done on this area. The final checks of Subthrust markers and structural data has been returned, and is being evaluated. It is believed that there will be a good result from these efforts when we understand the shape and characteristics of the subthrust a little better.

\section{$\underline{\text { Geology }}$}

Significant progress was made on fault verification. Because of the small throws on most of the faults in the field we needed to do additional work to verify fault plane angles. This was accomplished by plotting net sand thickness maps and then kriging the data. The wells were color coded based on the presence of an OWC. This technique proved to be very useful and will ultimately help us tie down the field faulting relationship.

Work continued on the oil/water contact summary maps. These maps show the configuration of the oil/water contact surface overlaid with isopachs of gross saturated interval. Well data points are posted with symbols displaying the saturation state of individual zone penetrations, i.e., fully oil saturated, wet, or containing an oil/water contact. Only the early well set has been used in the preparation of these maps so that the results represent a depiction of the original oil saturation of the reservoir. Preliminary fault patterns from well correlation work have also been overlaid for comparison with the saturation patterns. Maps have been completed for zones E4 through G3B on Leases P-0166. Preliminary results show that these maps will be a valuable tool for refining the fault pattern which will be the basis for the next generation of geologic modeling.

During May a one-week training seminar in Dynamic Graphic's EarthVision was held in the Ventura office. The complete process of building a 3-D geologic/attribute model was covered.

Work continued on the oil/water contact data which had been obtained from previous study of well logs. Maps were prepared for each zone showing an overlay of oil/water contact structure and total 
oil column thickness for Lease P-0166. These maps were posted with color coded well symbols which show the locations of wells with totally wet columns, totally oil saturated columns and recognized oil/water columns plotted at the appropriate X-Y position for each zone. Only early wells (pre-1974) were used on these plots to minimize the effect of prior production on oil/water contact levels. These maps depict our best estimate of the original reservoir saturation distribution for each zone and frequently show concentrations of hydrocarbon saturation along the plunge of the structure which must be due to some sort of migration barrier, probably faulting. On Lease P-0166 two of these areas correspond to the positions of the West Hogan and West Boundary faults, respectively, which had previously been mapped based on well correlation data. A third anomaly appeared in the area of Platform Houchin which seems to imply a previously unrecognized fault which we are calling Houchin-1 or HOU1) for present. The distribution of wells on the OWC/saturation maps sets limits on the possible locations of the faults which are considered to cause the saturation anomalies, and these limits have been quantified and entered into an Excel spreadsheet.

The presence of congruent saturation anomalies in vertically separated zones provides a third dimension for fault location. These data have been entered into EarthVision and examined with the 3-D viewer. After data conflicts were resolved, contouring was performed and .2grd and .plt files prepared in EarthVision. These fault planes will now be extended over the model space and checked for consistency with well data.

Zone top and base contact picking has been completed for the subthrust wells on leases P-0166 and PRC 3150. These picks are being entered into an Access database for matching with $\mathrm{X} / \mathrm{Y}$ location data, following which contour maps of each subthrust horizon will be prepared by SLC using Z-map to produce quick mapping results for quality control purposes before entering the subthrust data into the 3-D model. Isochore maps of the subthrust stratigraphic intervals between zone G3 and the Miocene were prepared in Surfer in support of quality control review of log picks previously made.

Also during June geologic effort was expended in support of the on-going rework/redrill program on Lease P-0166. Close coordination has been maintained between Production and Geology so that each group benefits from the expertise of the other as the workover program progresses.

The majority of geologic work during June was expended on an effort to finalize the fault interpretation in the suprathrust block of Lease P-0166, for inclusion in the model which will be delivered to the reservoir simulation group in July. Currently, a total of 6 faults are proposed for inclusion in the model; the East Boundary Fault, the West Boundary Fault, the West Hogan Fault, the newly recognized Houchin Fault, the North Fault and the Hobson Fault. The current fault interpretation has integrated the well log fault intercept picks made early in the project with results from the oil-water contact/fluid type/structure contour map overlays which were made in May and June. The resulting interpretation shows those faults that have a demonstrated effect on the distribution of reservoir fluids. EarthVision grid files were generated this month for these faults, and extended over the project area. From these, faces files have been prepared which can be displayed in the EV 3-D viewer with the intercept data points, allowing fine tuning of the fault plane orientation to obtain the best fit to all of the available data.

\section{Task 1.2.2 - Reservoir Performance}


Analysis of static pressure (Fluid Level Measurements) of 10/2/1996 on Wells A-43, A-44, A-47 and A-48 shows that Wells A-44 and A-48 are in two separate fault blocks (420 psi pressure difference). In the fault block where A-48 is located, only Well A-23 is producing.

Wells A-23 and A-26 both are opened to F-1, G-1 to G-3. A-26 is located up structure with respect to A-23 but its producing GOR is one half of A-23. Sands F-1, G-1 to G-3 may not be continuous between these two wells.

New fluid level measurements were conducted on A-41, A-43, A-44, A-47 and A-48 on April 30, 1997. The minimum bottom hole pressures corrected to the datum of -3300 feet ss (assuming a column of pure oil of 25 API gravity) in wells A-41, A-43, A-44, A-47 and A-48 were increased by $45,82,2,39$, and 437 psi respectively.

Further analysis of the aquifer system was achieved by using reservoir production history. Also simple single well models have been used to better understand the behavior of the commingled production decline.

Later in the reporting period, reservoir engineering efforts were primarily focused on engineering to support the proposed redrill program. This consisted of modifying the Monte Carlo economic model to consider the updated cost information, timing, and number of wells to be redrilled. As our engineering efforts have advanced, we have now determined that a six well redrill program is more beneficial, both from the perspective of spreading the rig mobilization expense, increasing the expected production increase, and the benefits of the additional reservoir information. Besides increasing cashflow, the redrill program will allow us to determine the current saturation state in the reservoir in several key locations.

\subsubsection{Management and Administration}

Monthly meetings were held with the participants in the project (USC, Coombs and Associates) to review the progress of various tasks.

\section{Task 1.3.2 - Planning for Budget Period II}

\section{Drilling Engineering}

A study was initiated to determine the cost feasibility and potential economic benefit of re-drilling existing P0166 wells. The concept is to evaluate recompleting selected existing wells by cutting a window in the existing casing above the top perfs and re-drilling the completion interval. We plan to evaluate the possibility of doing re-drills such as these with our existing rigs, or with a large workover rig versus mobilizing a drilling rig as we plan for the full horizontal program. Based on our study results, and on the early findings from the workover program (several wells with partially collapsed casing in the uppermost perforated interval) it may be advantageous to do a small re-drill program (6 to 8 wells) prior to the full horizontal program. This would have the advantage of obtaining current saturations in the targeted horizontal zones and increase production at the same 
time.

During April we continued the effort of planning a 6-8 well redrill program. 10 potential Hogan redrill candidates were selected. Further efforts resulted in development of a Monte Carlo model to estimate redrill costs. The cost estimate is based on drilling both conventional redrills and 500' horizontal redrills.

\subsubsection{Tech Transfer}

During this period we completed the following activities:

C Updated our Web site with current activities

C Presented SPE paper at the SPE Western Regional Meeting, Long Beach, CA during June. 